\title{
Noise Performance of Heterojunction DDR MITATT Devices Based on $\mathrm{Si} \sim \mathbf{S i}_{1-x} \mathbf{G e}_{x}$ at W-Band
}

\author{
Suranjana Banerjee, ${ }^{1}$ Aritra Acharyya, ${ }^{2}$ and J. P. Banerjee ${ }^{2}$ \\ ${ }^{1}$ Academy of Technology, West Bengal University of Technology, Adisaptagram, Hooghly, West Bengal 712121, India \\ ${ }^{2}$ Institute of Radio Physics and Electronics, University of Calcutta, 92 APC Road, Kolkata, West Bengal 700009, India \\ Correspondence should be addressed to Aritra Acharyya; ari_besu@yahoo.co.in
}

Received 24 February 2013; Accepted 5 April 2013

Academic Editor: Gerard Ghibaudo

Copyright ( 2013 Suranjana Banerjee et al. This is an open access article distributed under the Creative Commons Attribution License, which permits unrestricted use, distribution, and reproduction in any medium, provided the original work is properly cited.

\begin{abstract}
Noise performance of different structures of $\mathrm{Si} \sim \mathrm{Si}_{1-x} \mathrm{Ge}_{x}$ anisotype heterojunction double-drift region (DDR) mixed tunneling and avalanche transit time (MITATT) devices has been studied. The devices are designed for operation at millimeter-wave Wband frequencies. A simulation model has been developed to study the noise spectral density and noise measure of the device. Two different mole fractions $x=0.1$ and $x=0.3$ of Ge and corresponding four types of device structure are considered for the simulation. The results show that the $n-\mathrm{Si}_{0.7} \mathrm{Ge}_{0.3} \sim P$-Si heterojunction DDR structure of MITATT device excels all other structures as regards noise spectral density $\left(0.82 \times 10^{-16} \mathrm{~V}^{2} \mathrm{sec}\right)$ and noise measure $(33.09 \mathrm{~dB})$ as well as millimeter-wave properties such as DC-to-RF conversion efficiency $(20.15 \%)$ and CW power output (773.29 mW).
\end{abstract}

\section{Introduction}

Impact avalanche transit time (IMPATT) devices are noisy devices having an average noise level of $30-40 \mathrm{~dB}[1-4]$. The noise in IMPATT devices arises mainly from random nature of carrier generation by impact ionization and avalanche multiplication phenomena. The intrinsic avalanche noise in IMPATT device depends mainly on the carrier ionization rates in the base semiconductor material [5]. The group IVIV compound semiconductor, $\mathrm{Si}_{1-x} \mathrm{Ge}_{x}$ has been used as an important base material for both optoelectronic and microelectronic devices [6-9]. $\mathrm{Si}_{1-x} \mathrm{Ge}_{x}$ is a bandgap engineered material whose material properties depend on the Ge mole fraction $(x)[10]$.

Mixed tunneling avalanche transit time (MITATT) device is an important member of avalanche transit time (ATT) device family operating at higher millimeter-wave frequencies [11-23]. In 1958 W. T. Read [11] in his very early paper predicted that band-to-band tunneling phenomenon might limit the DC-to-RF conversion efficiency of the IMPATT diodes at high frequencies. Kwok and Haddad [12] reported the effect of tunneling on the negative conductance of the device. They considered that instantaneous carrier generation process through tunneling is equivalent to that of a fielddependent carrier source. This concept gave birth to new modes of IMPATT device, namely, MITATT and tunnel transit time (TUNNETT) modes. Nishizawa et al. [13] described the design and principle of the pulse oscillation characteristics of GaAs TUNNETT diodes. Elta and Haddad [14, 15] analyzed the high frequency performance of IMPATT diode by using a modified Read-type equation and considering dead space correction for impact ionization for the charge carriers. They proposed that the above mentioned three different modes (pure IMPATT, MITATT, and TUNNETT modes) of operation of IMPATT depend on the width of avalanche region. Luy and Kuehnf [16] found that the device efficiency decreases due to tunnel generated carriers. A generalized computer simulation method for MITATT mode based on the model proposed by Roy et al. [17, 18] was later reported [19]. Elta [20] and Kane [21] showed that the performance of IMPATT devices deteriorates due to tunneling-induced phase distortion. Eisele and Haddad [22] also carried out experimental work on TUNNETT mode operation of IMPATT diodes grown on diamond heat sink. They reported highest RF conversion efficiency of TUNNETT devices. According to [23], special designs of 


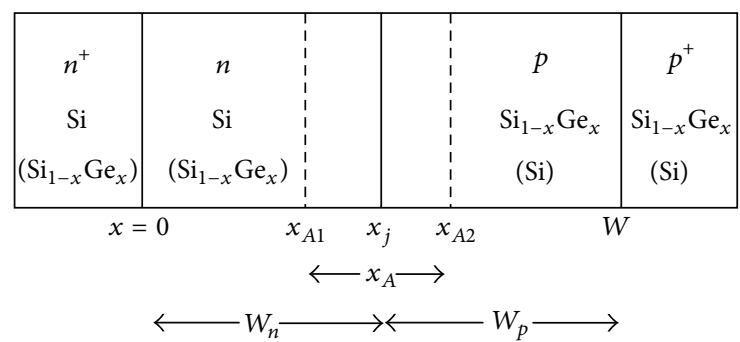

FIgURE 1: One-dimensional schematics of the $\mathrm{Si} \sim \mathrm{Si}_{1-x} \mathrm{Ge}_{x}$ anisotype heterojunction DDR MITATT devices.

MITATT devices can provide higher efficiency, higher output power, and lower noise as compared to normal IMPATT diodes. The effect of tunneling on the high frequency properties of DDR Si IMPATTs operating at millimeter-wave and terahertz frequencies was studied and reported by Acharyya et al. in their earlier paper $[24,25]$ which showed that the critical background doping concentration and operating frequency above which tunneling effect becomes predominant are $5.0 \times 10^{23} \mathrm{~m}^{-3}$ and $260 \mathrm{GHz}$, respectively. The millimeterwave performance of IMPATTs operating in MITATT mode was studied by Acharyya et al. from the shift of avalanche transit time (ATT) phase delay and reported in [26]. The reported results show that with increasing frequency the shift of ATT phase delay increases which explains the physical reason behind the deterioration of millimeter-wave performance of the device at higher frequencies. Since tunneling is a noiseless phenomenon, it is expected that the noise level in MITATTs will be lower than that in IMPATTs. Furthermore, it is reported [27] that heterojunction IMPATTs have lower noise level than their homojunction counterparts. All these facts have inspired the authors to study the noise performance of four types of $\mathrm{Si} \sim \mathrm{Si}_{1-x} \mathrm{Ge}_{x}$ anisotype heterojunction DDR structures of MITATT devices at W band. In this study, only two different mole fractions of Ge, $x=0.1$ and $x=$ 0.3 , are considered. The performance of different structures of heterojunction DDR MITATTs is compared with their homojunction counterpart based on Si operating at the same frequency band.

\section{Simulation Method to Study the Noise Properties}

One-dimensional model of reverse biased $\mathrm{Si} \sim \mathrm{Si}_{1-x} \mathrm{Ge}_{x}$ DDR MITATT device shown in Figure 1 is considered for noise analysis. The DC electric field and current density profiles in the depletion layer of the device are obtained from simultaneous numerical solution of fundamental device equations, that is, Poisson's equation, combined carrier continuity equation in the steady state, current density equations, and mobile space charge equation subject to appropriate boundary conditions as discussed in detail in the earlier papers by the authors of [24-26]. A double-iterative simulation method described elsewhere [17] is used to solve these equations and to obtain the electric field and current density profiles. The boundary conditions for the electric field at the depletion layer edges, that is, at $x=0$ and $x=W$, are given by

$$
\xi(0)=0, \quad \xi(W)=0 .
$$

Similarly, the boundary conditions for normalized current density $P(x)=\left(J_{p}(x)-J_{n}(x)\right) / J_{0}$ (where the total current density $J_{0}=J_{n}(x)+J_{p}(x)$, where $J_{n}(x)$ and $J_{p}(x)$ are the electron and hole current densities, respectively, at the space point $x$ ) at the depletion layer edges are given by

$$
P(0)=\left(\frac{2}{M_{p}(0)}-1\right), \quad P(W)=\left(1-\frac{2}{M_{n}(W)}\right)
$$

where $M_{n}(W)$ and $M_{p}(0)$ are, respectively, the electron and hole multiplication factors at the depletion layer edges whose values are of the order of $10^{6}$ under dark or unilluminated condition of the device.

The magnitude of peak field at the junction $\left(\xi_{p}\right)$, breakdown voltage $\left(V_{B}\right)$, the widths of avalanche and drift zones $\left(x_{A}\right.$ and $x_{D}$, where $\left.x_{D}=d_{n}+d_{p}\right)$, and the voltage drops across these zones $\left(V_{A}, V_{D}=V_{B}-V_{A}\right)$ are obtained from doubleiterative DC simulation program. These values are fed back as input parameters in the small-signal simulation program to obtain the admittance properties of the device such as avalanche resonance frequency $\left(f_{a}\right)$, optimum frequency $\left(f_{p}\right)$, negative conductance $(G(\omega))$, and corresponding susceptance $(B(\omega))$ as functions of frequency. Two secondorder differential equations are framed by resolving the diode impedance $Z(x, \omega)$ into its real part $R(x, \omega)$ and imaginary part $X(x, \omega)[18,19,24,25,28-31]$. Here, $Z(x, \omega)=R(x, \omega)+$ $j X(x, \omega)$, where $R(x, \omega)$ and $X(x, \omega)$ are, respectively, the negative specific resistance and specific reactance at the space point $x$, for angular frequency of $\omega$ (frequency $f=2 \pi / \omega$ ). A double-iterative simulation over the initial choice of the values of $R$ and $X$ described in details in [18] is used to solve simultaneously the two above said second order differential equations subject to appropriate boundary conditions at the depletion layer edges. The spatial profiles of negative specific resistance and specific reactance (i.e., $R(x, \omega)$ versus $x$ and $X(x, \omega)$ versus $x)$ for a particular frequency are obtained from the above solution within the depletion layer of the device. The device negative resistance $\left(Z_{R}(\omega)\right)$ and reactance $\left(Z_{X}(\omega)\right)$ are obtained from the numerical integration of the $R(x, \omega)$ and $X(x, \omega)$ profiles over the space-charge layer width $(W)$. Thus,

$$
Z_{R}(\omega)=\int_{0}^{W} R(x, \omega) d x, \quad Z_{X}(\omega)=\int_{0}^{W} X(x, \omega) d x
$$

The impedance of the device is given by $Z_{D}(\omega)=Z_{R}(\omega)+$ $j Z_{X}(\omega)$ and the device admittance is $Y_{D}(\omega)=1 / Z_{D}(\omega)=$ $G(\omega)+j B(\omega)$. The negative conductance and corresponding 
susceptance at different frequencies are computed from the following expressions:

$$
\begin{aligned}
& |G(\omega)|=\frac{Z_{R}(\omega)}{\left(Z_{R}(\omega)^{2}+Z_{X}(\omega)^{2}\right)}, \\
& |B(\omega)|=\frac{-Z_{X}(\omega)}{\left(Z_{R}(\omega)^{2}+Z_{X}(\omega)^{2}\right)} .
\end{aligned}
$$

The random nature of the impact ionization process is the main source of noise in avalanche transit time (ATT) devices. This random impact ionization process gives rise to fluctuations in the DC current and DC electric field which appear as small-signal components to their DC values even in the absence of voltage variation across the device. Open circuit condition without any variation of applied voltage is considered for the noise analysis of IMPATT/MITATT device. Starting from the small-signal AC field due to noise $e\left(x, x^{\prime}\right)=e_{r}\left(x, x^{\prime}\right)+j e_{i}\left(x, x^{\prime}\right)$, two second-order differential equations are framed corresponding to the real $\left(e_{r}\left(x, x^{\prime}\right)\right)$ and imaginary $\left(e_{i}\left(x, x^{\prime}\right)\right)$ parts of the noise electric field $e\left(x, x^{\prime}\right)$. This field is assumed to be due to a noise source $\gamma\left(x^{\prime}\right)$ located at space point $x^{\prime}$ within the depletion region of the device [32-34]. The numerical solution of two simultaneous differential equations involving the real and imaginary parts of noise electric field $e\left(x, x^{\prime}\right)$ is carried out by using a double-iterative technique, and Runge-Kutta method subject to the satisfaction of appropriate boundary conditions at the depletion layer edges [32-34]. The noise source $\gamma\left(x^{\prime}\right)$ is first considered to be located at one edge of the depletion region. The noise source is then shifted to the next space point and the procedure is repeated until the entire depletion region is covered and the other edge of the depletion layer is reached. Numerical integration of noise electric field $e\left(x, x^{\prime}\right)$ over the entire depletion layer provides the terminal voltage $V_{T}\left(x^{\prime}\right)$ produced by noise source, that is,

$$
V_{T}\left(x^{\prime}\right)=\int_{0}^{W} e\left(x, x^{\prime}\right) d x .
$$

The transfer impedance of the device is defined as

$$
Z_{T}\left(x^{\prime}\right)=\frac{V_{T}\left(x^{\prime}\right)}{I_{N}\left(x^{\prime}\right)},
$$

where $I_{N}\left(x^{\prime}\right)$ is the average current generated in the interval $d x^{\prime}$ due to $\gamma\left(x^{\prime}\right)$ located at $x^{\prime}$. The mean-square noise voltage is obtained from

$$
\left\langle v_{n}^{2}\right\rangle=2 q^{2} \cdot d f \cdot A \int\left|Z_{T}\left(x^{\prime}\right)\right|^{2} \gamma\left(x^{\prime}\right) d x^{\prime} .
$$

Mean-square noise voltage per bandwidth is called noise spectral density $\left(\left\langle v_{n}^{2}\right\rangle / d f \mathrm{~V}^{2}\right.$ sec). The noise performance of the device can be known from a parameter called the noise measure (NM) defined as

$$
\mathrm{NM}=\frac{\left\langle v_{n}^{2}\right\rangle / d f}{4 K_{B} T\left(-Z_{R}-R_{S}\right)},
$$

where $K_{B}$ is the Boltzmann constant $\left(K_{B}=1.38 \times 10^{-23} \mathrm{~J} \mathrm{~K}^{-1}\right)$, $T$ is the absolute temperature, $Z_{R}$ is the device negative resistance, and $R_{S}$ is the positive parasitic series resistance associated with the device.

\section{Material Parameters and Design}

The realistic field dependence of ionization rates $\left(\alpha_{n}, \alpha_{p}\right)$ and drift velocities $\left(v_{n}, v_{p}\right)$ of $\mathrm{Si}$ and $\mathrm{Si}_{1-x} \mathrm{Ge}_{x}(x=0.1$ and $x=$ 0.3 ) at realistic junction temperature of $500 \mathrm{~K}$ are taken from the recently published experimental reports [35-40]. Other material parameters of $\mathrm{Si}$ and $\mathrm{Si}_{1-x} \mathrm{Ge}_{x}(x=0.1$ and $x=0.3)$ such as intrinsic carrier concentration $\left(n_{i}\right)$, effective density of states of conduction and valance bands $\left(N_{c}, N_{v}\right)$, diffusion coefficients $\left(D_{n}, D_{p}\right)$, mobilities $\left(\mu_{n}, \mu_{p}\right)$ and diffusion lengths $\left(L_{n}, L_{p}\right)$ of charge carriers, and permittivity $\left(\varepsilon_{s}\right)$ are taken from the published data given in [10]. The active layer widths $\left(W_{n}, W_{p}\right)$ and doping concentrations $\left(N_{D}, N_{A}\right)$ of all different structures of MITATTs under consideration are designed following a width modulated design method suggested for MITATT devices in [23] for operation at $94 \mathrm{GHz}$ atmospheric window frequency. The doping concentrations of the $n^{+}$- and $p^{+}$-layers $\left(N_{n^{+}}, N_{p^{+}}\right)$are taken to be in the order of $10^{25}$ for W-band operation. The designed doping and structural parameters are listed in Table 1.

\section{Results and Discussion}

The authors have used a double-iterative simulation method $[18,19,24,25,28-31]$ to study the static and high-frequency properties of homojunction $(N-\mathrm{Si} \sim \mathrm{P}$-Si) and heterojunction $\left(N-\mathrm{Si} \sim p-\mathrm{Si}_{0.9} \mathrm{Ge}_{0.1}, N-\mathrm{Si} \sim p-\mathrm{Si}_{0.7} \mathrm{Ge}_{0.3}, n-\mathrm{Si}_{0.9} \mathrm{Ge}_{0.1} \sim\right.$ $P$-Si and $n$ - $\mathrm{Si}_{0.7} \mathrm{Ge}_{0.3} \sim P$-Si) DDR IMPATTs operating at $94 \mathrm{GHz}$ atmospheric window. Peak tunneling generation rate $\left(q G_{\mathrm{Tp}}\right)$, peak avalanche generation rate $\left(q G_{\mathrm{Ap}}\right)$, and ratio of $G_{\mathrm{Tp}}$ to $G_{\mathrm{Ap}}\left(G_{\mathrm{Tp}} / G_{\mathrm{Ap}}(\%)\right)$ of all the devices under consideration are listed in Table 2. The ratio $G_{\mathrm{Tp}} / G_{\mathrm{Ap}}(\%)$ is very high $(31.69 \%)$ in $\mathrm{Si}$ homojunction DDR IMPATT. Thus, the phase distortion associated with tunneling results in deterioration of RF performance of the Si homojunction device and the device operates in MITATT mode. But the same $\left(G_{\mathrm{Tp}} / G_{\mathrm{Ap}}(\%)\right)$ is very small around $0.06 \%-0.29 \%$ in the $\mathrm{Si} \sim \mathrm{Si}_{1-x} \mathrm{Ge}_{x}$ heterojunction DDRs, which indicates that those devices operate in pure IMPATT mode (without considerable amount of band-to-band tunneling) at $94 \mathrm{GHz}$.

The simulated DC parameters such as peak electric field $\left(\xi_{p}\right)$, breakdown voltage $\left(V_{B}\right)$, avalanche voltage $\left(V_{A}\right)$, avalanche layer width $\left(x_{A}\right)$, ratio of avalanche layer width to total depletion layer width $\left(x_{A} / W(\%)\right.$, where $\left.W=W_{n}+W_{p}\right)$ and DC-to-RF conversion efficiency $(\eta)$ of all the devices at the respective bias current densities $\left(J_{0}\right)$ are given in Table 3 . Figure 2 shows the electric field profiles of those devices. It is evident from Figure 2 and Table 3 that the heterojunction DDRs require lower field at breakdown as compared to their $\mathrm{Si}$ homojunction counterpart. Breakdown voltage $\left(V_{B}\right)$ is obtained by numerical integration of electric field profile over the depletion layer width (i.e., from $x=0$ to $x=W$ ). The simulated values of breakdown voltage of heterojunction 
TABLE 1: Design parameters.

\begin{tabular}{lccccccc}
\hline Structures $^{*}$ & $W_{n}(\mu \mathrm{m})$ & $W_{p}(\mu \mathrm{m})$ & $N_{D}\left(\times 10^{23} \mathrm{~m}^{-3}\right)$ & $N_{A}\left(\times 10^{23} \mathrm{~m}^{-3}\right)$ & $N_{n^{+}}\left(\times 10^{25} \mathrm{~m}^{-3}\right)$ & $N_{p^{+}}\left(\times 10^{25} \mathrm{~m}^{-3}\right)$ & $D_{j}(\mu \mathrm{m})^{\dagger}$ \\
\hline NSPS & 0.40 & 0.38 & 1.20 & 1.25 & 5.0 & 5.0 & 2.7 \\
NSpSG1 & 0.34 & 0.32 & 0.85 & 0.85 & 5.0 & 2.7 \\
NSpSG2 & 0.34 & 0.30 & 0.85 & 0.78 & 5.0 & 2.7 & 35.0 \\
nSGPS1 & 0.32 & 0.32 & 0.0 & 5.0 & 35.0 \\
nSGPS2 & 0.34 & 0.32 & 0.85 & 0.90 & 5.0 & 2.7 \\
\hline
\end{tabular}

*NSPS: N-Si $\sim P$-Si homojunction DDR MITATT.

*NSpSG1: $N-\mathrm{Si} \sim p-\mathrm{Si}_{0.9} \mathrm{Ge}_{0.1}$ anisotype heterojunction DDR MITATT.

${ }^{*} \mathrm{NSpSG2:} \mathrm{N}-\mathrm{Si} \sim p-\mathrm{Si}_{0.7} \mathrm{Ge}_{0.3}$ anisotype heterojunction DDR MITATT.

*nSGPS1: $n$-Si ${ }_{0.9} \mathrm{Ge}_{0.1} \sim P$-Si anisotype heterojunction DDR MITATT.

${ }^{*}$ nSGPS2: $n$ - $\mathrm{Si}_{0.7} \mathrm{Ge}_{0.3} \sim P$-Si anisotype heterojunction DDR MITATT.

${ }^{\dagger} D_{j}$ : is the diameter of the $\mathrm{p}-\mathrm{n}$ junction.

TABLE 2: Values of $q G_{\mathrm{Tp}}, q G_{\mathrm{Ap}}$, and $G_{\mathrm{Tp}} / G_{\mathrm{Ap}}$.

\begin{tabular}{lrcccc}
\hline Parameters & NSPS & NSpSG1 & NSpSG2 & nSGPS1 & nSGPS2 \\
\hline$q G_{\mathrm{Tp}}\left(\times 10^{12} \mathrm{~m}^{-3} \mathrm{sec}^{-1}\right)$ & 552.87 & 6.3498 & 3.6309 & 3.8271 & 1.4560 \\
$q G_{\mathrm{Ap}}\left(\times 10^{15} \mathrm{~m}^{-3} \mathrm{sec}^{-1}\right)$ & 1.7441 & 4.5615 & 3.5989 & 1.3303 & 2.2810 \\
$G_{\mathrm{Tp}} / G_{\mathrm{Ap}}(\%)$ & 31.69 & 0.14 & 0.10 & 0.29 & 0.06 \\
\hline
\end{tabular}

TABLE 3: Millimeter-wave and noise properties.

\begin{tabular}{lccccc}
\hline Parameters & NSPS & NSpSG1 & NSpSG2 & nSGPS1 & nSGPS2 \\
\hline$J_{0}\left(\times 10^{8} \mathrm{~A} \mathrm{~m}^{-2}\right)$ & 2.8 & 3.0 & 3.2 & 3.3 & 3.6 \\
$\xi_{p}\left(\times 10^{7} \mathrm{~V} \mathrm{~m}^{-1}\right)$ & 6.0125 & 3.6760 & 3.5666 & 3.5534 & 3.3656 \\
$V_{B}(\mathrm{~V})$ & 23.89 & 12.89 & 11.81 & 11.40 & 11.08 \\
$V_{A}(\mathrm{~V})$ & 16.34 & 6.67 & 6.06 & 4.37 & 4.07 \\
$x_{A}(\mu \mathrm{m})$ & 0.354 & 0.210 & 0.204 & 0.166 & 0.162 \\
$x_{A} / W(\%)$ & 45.39 & 31.82 & 31.86 & 25.94 & 24.55 \\
$\eta(\%)$ & 10.06 & 15.36 & 15.49 & 19.64 & 20.15 \\
$f_{p}(\mathrm{GHz})$ & 106 & 94 & 96 & 95 & 94 \\
$G_{p}\left(\times 10^{7} \mathrm{~S} \mathrm{~m}^{-2}\right)$ & 4.6593 & 8.3760 & 10.594 & 10.441 & 11.790 \\
$B_{p}\left(\times 10^{7} \mathrm{~S} \mathrm{~m}^{-2}\right)$ & 17.320 & 12.252 & 9.0710 & 12.102 & 4.2031 \\
$Q_{p}\left(=-B_{p} / G_{p}\right)$ & 3.72 & 1.46 & 0.86 & 1.16 & 0.36 \\
$Z_{R}\left(\times 10^{-9} \Omega \mathrm{m}^{2}\right)$ & 1.4484 & 3.8026 & 5.4463 & 4.0869 & 7.5254 \\
$P_{\mathrm{RF}}(\mathrm{mW})$ & 647.44 & 571.47 & 563.22 & 710.86 & 773.29 \\
$\left\langle v_{n}^{2}\right\rangle / d f$ & & & & & \\
$\left(\times 10^{-16} \mathrm{~V}^{2} \mathrm{sec}^{2}\right)$ & 39.51 & 3.75 & 1.85 & 1.39 & 0.82 \\
$\mathrm{NM}(\mathrm{dB})$ & 40.00 & 37.42 & 36.54 & 34.27 & 33.09 \\
\hline
\end{tabular}

devices are lower than that of homojunction device. Again the avalanche voltage drop can be obtained from numerical integration of the electric field profiles over the avalanche region (i.e., from $x=x_{A 1}$ to $x=x_{A 2}$ ). The avalanche voltages of heterojunction MITATTs are found to be smaller than that of homojunction device. Narrower avalanche widths of heterojunction MITATTs indicate sharper growth of normalized current density profiles $(P(x)$ versus $x)$. The sharper the growth of $P(x)$ profile, the narrower the avalanche zone. This leads to higher DC-to-RF conversion efficiency $(\eta)$ of heterojunction devices as compared to their homojunction counterpart based on Si [41]. Table 3 further shows that this

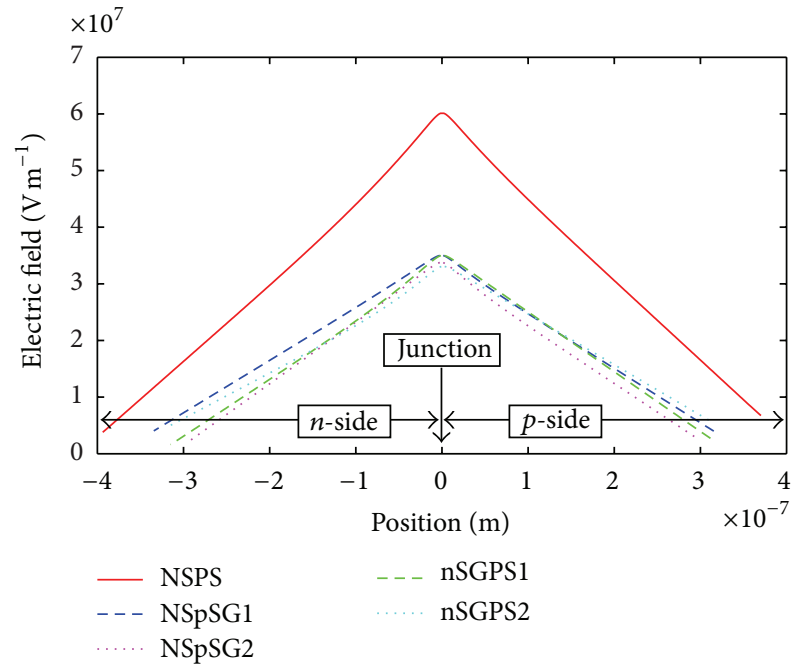

FIGURE 2: Electric field profiles of the DDR MITATT devices.

efficiency is the highest in $n-\mathrm{Si}_{0.7} \mathrm{Ge}_{0.3} \sim P$-Si heterojunction DDR device $(20.15 \%)$ of all other types of DDRs.

The admittance characteristics of the devices under consideration are shown in Figure 3. Table 3 shows that magnitude of the peak negative conductance $\left(G_{p}\right)$ and negative resistance $\left(Z_{R}\right)$ are higher for heterojunction MITATTs as compared to those for $\mathrm{Si}$ homojunction counterpart. It may be noted that the above parameters $\left(G_{p}, Z_{R}\right)$ are maximum for $n-\mathrm{Si}_{0.7} \mathrm{Ge}_{0.3} \sim P$-Si heterojunction structure (nSGPS2). Also power output $\left(P_{\mathrm{RF}}\right)$ from that particular structure (nSGPS2) is the highest $(773.29 \mathrm{~mW})$ as compared to that from all other structures. The lowest value of $Q$-factor $\left(Q_{p}=-B_{p} / G_{p}=0.36\right)$ in that structure (nSGPS2) indicates growth rate and stability of IMPATT oscillation. The spatial variations of negative resistivity of all structures of MITATT devices are shown in Figure 4. All these negative resistivity profiles exhibit two peaks in the two drift regions with a minimum in the avalanche region. The magnitude of negative resistivity peaks in both the drift layers is the highest in that structure (nSGPS2) compared to those of other structures.

Furthermore, it is interesting to observe from Table 3 that, though the breakdown voltage $\left(V_{B}\right)$ of $n-\mathrm{Si}_{0.9} \mathrm{Ge}_{0.1} \sim P$-Si and 


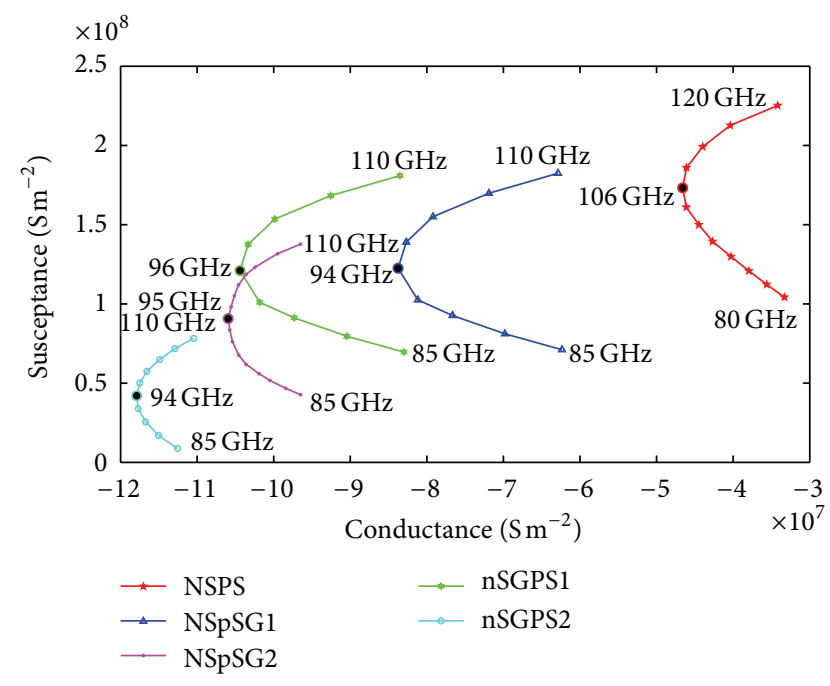

FIGURE 3: Admittance characteristics of the DDR MITATT devices.

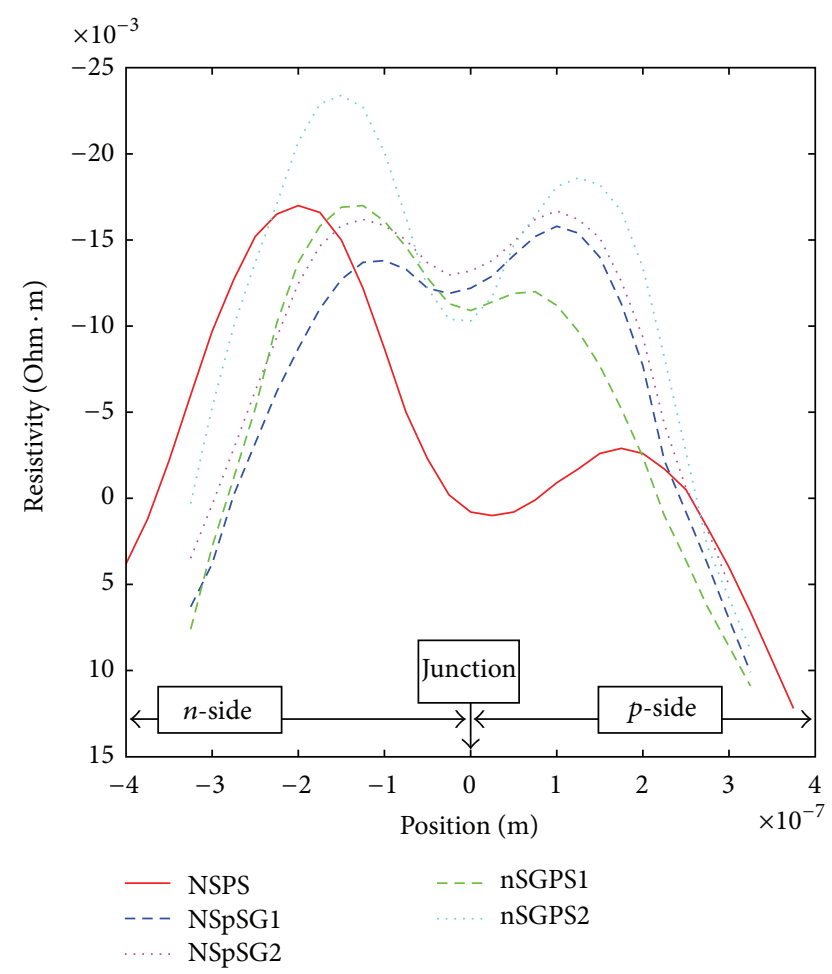

FIGURE 4: Negative resistivity profiles of the DDR MITATT devices.

$n$ - $\mathrm{Si}_{0.7} \mathrm{Ge}_{0.3} \sim P$-Si heterojunction DDRs is almost half of that of Si homojunction DDR due to much smaller breakdown field in $\mathrm{Si}_{1-x} \mathrm{Ge}_{x}$ than that of $\mathrm{Si}[10,37-39]$, the RF power output $\left(P_{\mathrm{RF}}=\eta \times V_{B} \times J_{0} \times A_{j}\right)$ which is proportional to both the breakdown voltage $\left(V_{B}\right)$ and DC-to-RF conversion efficiency $(\eta)$ of those heterojunction devices is higher as compared to that of their homojunction counterpart due to much larger DC-to-RF conversion efficiency $(\eta)$ of those above said heterojunction devices.

Figures 5 and 6 show, respectively, the simulated noise spectral densities $\left(\left\langle v_{n}^{2}\right\rangle / d f\right)$ and noise measures (NM) against

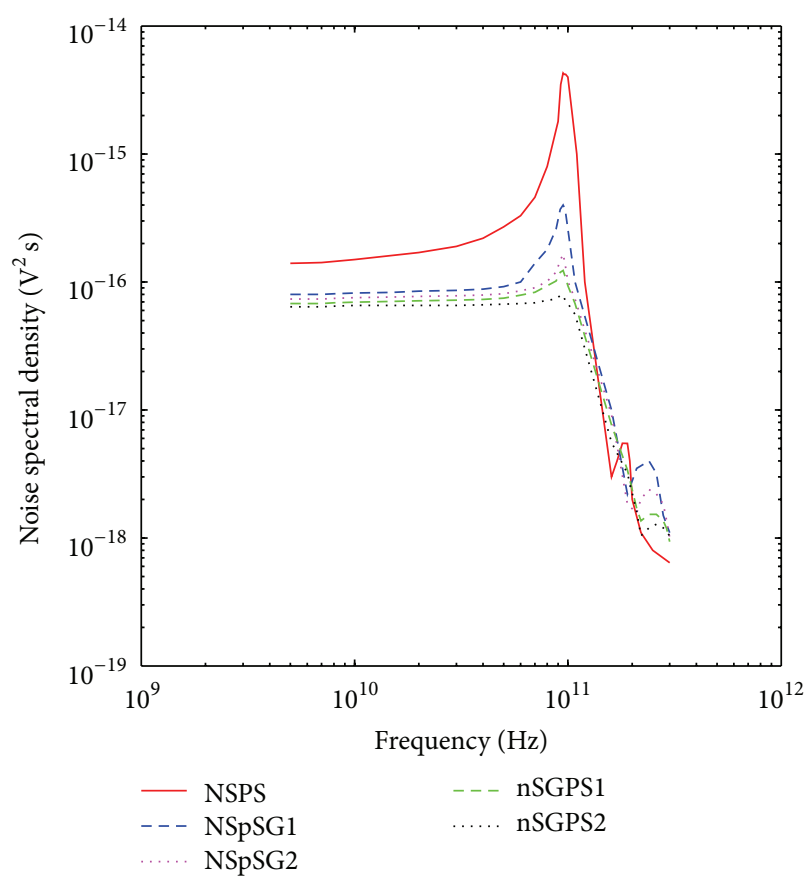

FIGURE 5: Variations of noise spectral densities $\left(\left\langle v_{n}^{2}\right\rangle / d f \mathrm{~V}^{2} \mathrm{sec}\right)$ of DDR MITATT devices with frequency.

frequency of $\mathrm{Si} \sim \mathrm{Si}_{1-x} \mathrm{Ge}_{x}$ heterojunction and $\mathrm{Si}$ homojunction DDR MITATT devices. It is observed that both NSD and NM are minimum $\left(0.82 \times 10^{-16} \mathrm{~V}^{2}\right.$ sec and $\left.33.09 \mathrm{~dB}\right)$ in $n$ - $\mathrm{Si}_{0.7} \mathrm{Ge}_{0.3} \sim P$-Si heterojunction DDR MITATT device at $94 \mathrm{GHz}$. The minimum noise level in that particular structure is due to suppression of noisy impact ionization phenomena in the narrowest avalanche zone.

The simulation results presented in this paper are cross checked with the previously reported experimentally obtained results to validate the simulation scheme adopted by the authors. Luy et al. [42] experimentally obtained CW power output of $600 \mathrm{~mW}$ at $94 \mathrm{GHz}$ with $6.7 \%$ efficiency in Si homojunction flat DDR in 1987. Latter, Dalle et al. [43] measured CW power output of about $500 \mathrm{~mW}$ at $94 \mathrm{GHz}$ with $8.0 \%$ conversion efficiency in 1990 . These experimental results are in close agreement with the simulation results presented in this paper for Si homojunction flat DDR (Table 3). The slight discrepancy in the simulated and experimentally reported values RF power output and DC-to-RF conversion efficiency may be due to the slight difference in the design parameters and DC bias current density. The first experimental results on $\mathrm{Si} / \mathrm{Si}_{1-x} \mathrm{Ge}_{x}$ heterostructure mixed tunneling avalanche transit time (MITATT) diodes were reported by Luy et al. [44] in 1988. They obtained $25 \mathrm{~mW}$ of RF power output with $1.3 \%$ of conversion efficiency at $103 \mathrm{GHz}$. But they used $\mathrm{Si}_{0.4} \mathrm{Ge}_{0.6}$ alloy to fabricate $\mathrm{Si} / \mathrm{Si}_{1-x} \mathrm{Ge}_{x}$ heterostructure. Due to this fact and also due to lack of optimization of their design, they obtained such lower power output and lower efficiency, but the simulation results presented in this paper with optimized design of the device predicting the fact that the $\mathrm{Si} / \mathrm{Si}_{1-x} \mathrm{Ge}_{x}$ heterojunction DDRs especially the $n P$ $\mathrm{Si}_{0.7} \mathrm{Ge}_{0.3} / \mathrm{Si}$ heterojunction DDRs are capable of delivering 


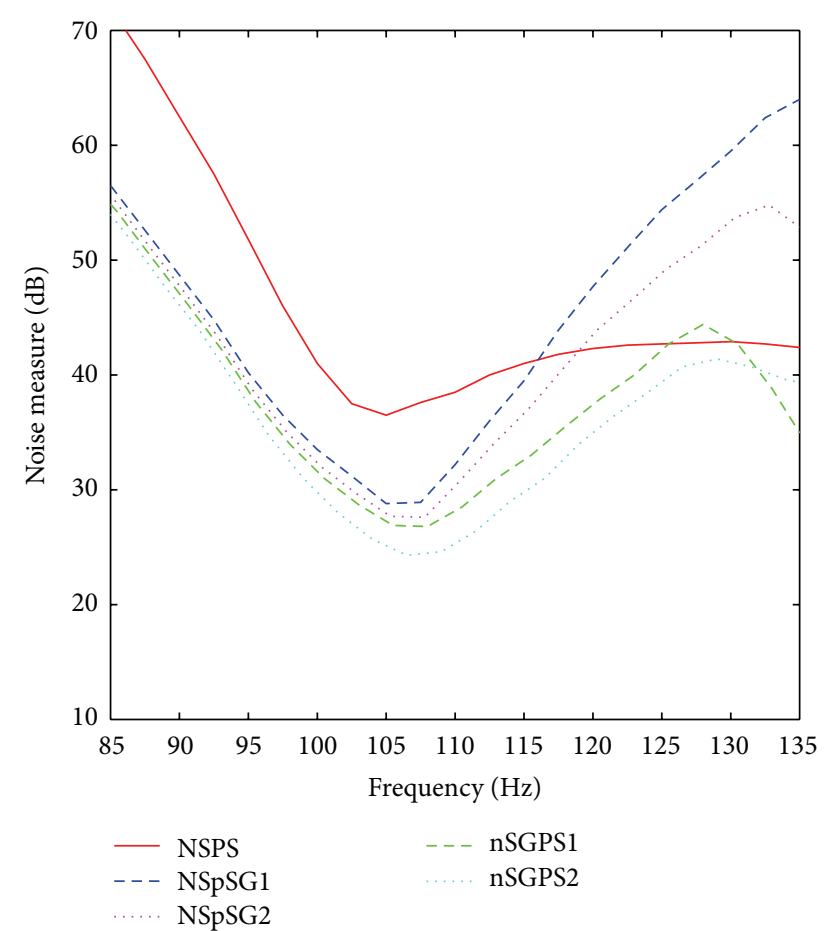

FIgURE 6: Noise measures (NM) versus frequency curves of DDR MITATT devices.

much larger power with much larger conversion efficiency as compared to the experimentally obtained values. Thus the suitable choice of Ge mole fraction $(x)$ of $\mathrm{Si}_{1-x} \mathrm{Ge}_{x}$, device structure, and proper optimization in design of the device are essential for getting expected RF power output.

\section{Conclusions}

In this paper, the authors have made an attempt to study the millimeter-wave and noise properties of different structures of $\mathrm{Si} \sim \mathrm{Si}_{1-x} \mathrm{Ge}_{x}$ anisotype heterojunction DDR MITATT devices. This simulation study clearly indicates that the $n$ $\mathrm{Si}_{0.7} \mathrm{Ge}_{0.3} \sim P$-Si heterojunction MITATT is the most suitable structure for generation of high RF power with high conversion efficiency and low noise measure. The results are extremely encouraging for the experimentalists to fabricate the $n-\mathrm{Si}_{0.7} \mathrm{Ge}_{0.3} \sim P$-Si heterojunction MITATTs for millimeter-wave applications.

\section{References}

[1] M. E. Hines, "Noise theory for the Read type avalanche diode," IEEE Transactions on Electron Devices, vol. 13, no. 1, pp. 158-163, 1966.

[2] H. K. Gummel and J. L. Blue, "A small-signal theory of avalanche noise in IMPATT diodes," IEEE Transactions on Electron Devices, vol. 14, pp. 569-580, 1967.

[3] H. A. Haus, H. Statz, and R. A. Pucel, "Optimum noise measure of IMPATT diodes," IEEE Transactions on Microwave Theory and Techniques, vol. 19, no. 10, pp. 801-813, 1971.
[4] R. L. Kuvas, "Noise in IMPATT diodes. Intrinsic properties," IEEE Transactions on Electron Devices, vol. 19, no. 2, pp. 220233, 1972.

[5] J. Banerjee, K. Roy, and M. Mitra, "Effect of negative resistance in the noise behavior of Ka-Band IMPATT diodes," International Journal of Engineering Science and Technology, vol. 4, no. 7, pp. 3584-3691, 2012.

[6] Z. Pei, C. S. Liang, L. S. Lai et al., "A high-performance SiGe-Si multiple-quantum-well heterojunction phototransistor," IEEE Electron Device Letters, vol. 24, no. 10, pp. 643-645, 2003.

[7] A. Acharyya and J. P. Banerjee, "A comparative study on the effect of optical illumination on $\mathrm{Si}_{1-x} \mathrm{Ge}_{x}$ and $\mathrm{Si}$ based DDR IMPATT diodes at W-band," Iranian Journal of Electronics and Electrical Engineering, vol. 7, no. 3, pp. 179-189, 2011.

[8] A. Acharyya and J. P. Banerjee, "A comparative study on the effects of tunneling on W-band $\mathrm{Si}$ and $\mathrm{Si}_{1-x} \mathrm{Ge}_{x}$ based doubledrift IMPATT devices," in IEEE International Conference on Electronics Computer Technology, Kanyakumari, India, April 2012.

[9] A. Acharyya and J. P. Banerjee, "Studies on anisotype Si/ $\mathrm{Si}_{1-x} \mathrm{Ge}_{x}$ heterojunction DDR IMPATTs: efficient millimeterwave sources at $94 \mathrm{GHz}$ window," IETE Journal of Research, vol. 59, no. 3, pp. 1-9, 2013.

[10] "Electronic Archive: New Semiconductor Materials, Characteristics and Properties," 2012, http://www.ioffe.ru/SVA/NSM/ Semicond.

[11] W. Shockley, "Negative resistance arising from transit time in semiconductor diodes," Bell System Technical Journal, vol. 33, pp. 799-826, 1954.

[12] S. P. Kwok and G. I. Hadded, "Effects of tunnelling on an IMPATT oscillator," Journal of Applied Physics, vol. 43, pp. 38243860, 1972.

[13] J. Nishizawa, K. Motoya, and Y. Okuno, "GaAs TUNNET diodes," IEEE Transactions on Microwave Theory and Techniques, vol. 26, no. 12, pp. 1029-1035, 1978.

[14] E. M. Elta and G. I. Haddad, "High frequency limitations of IMPATT, MITATT and TUNNETT mode devices," IEEE Transactions on Microwave Theory and Techniques, vol. 27, no. 5, pp. 442-449, 1979.

[15] E. M. Elta and G. I. Hadded, "Mixed tunnelling and avalanche mechanism in p-n junctions and their effects on microwave transit-time devices," IEEE Transactions on Electron Devices, vol. 25, no. 6, pp. 694-702, 1978.

[16] J. F. Luy and R. Kuehnf, "Tunneling-assisted IMPATT operation," IEEE Transactions on Electron Devices, vol. 36, no. 3, pp. 589-595, 1989.

[17] S. K. Roy, M. Sridharan, R. Ghosh, and B. B. Pal, "Computer method for the dc field and carrier current profiles in the IMPATT device starting from the field extremum in the depletion layer," in Proceedings of the 1st Conference on Numerical Analysis of Semiconductor Devices (NASECODE I '79), J. H. Miller, Ed., pp. 266-274, Dublin, Ireland, 1979.

[18] S. K. Roy, J. P. Banerjee, and S. P. Pati, "A Computer analysis of the distribution of high frequency negative resistance in the depletion layer of IMPATT Diodes," in Proceedings of the 4th Conference on Numerical Analysis of Semiconductor Devices (NASECODE IV'85), pp. 494-500, Dublin, Ireland, 1985.

[19] G. N. Dash and S. P. Pati, "A generalized simulation method for MITATT-mode operation and studies on the influence of tunnel current on IMPATT properties," Semiconductor Science and Technology, vol. 7, no. 2, pp. 222-230, 1992. 
[20] M. E. Elta, The effect of mixed tunneling and avalanche breakdown on microwave transit-time diodes [Ph.D.dissertation], Electron Physics Laboratory, University of Michigan, Ann Arbor, Mich, USA, 1978.

[21] E. O. Kane, "Theory of tunneling," Journal of Applied Physics, vol. 32, pp. 83-91, 1961.

[22] H. Eisele and G. I. Haddad, "GaAs TUNNETT diodes on diamond heat sink for $100 \mathrm{GHz}$ and above," IEEE Transactions on Microwave Theory and Techniques, vol. 43, no. 1, pp. 210-213, 1995.

[23] G. N. Dash, "A new design approach for MITATT and TUNNETT mode devices," Solid-State Electronics, vol. 38, no. 7, pp. 1381-1385, 1995.

[24] A. Acharyya, M. Mukherjee, and J. P. Banerjee, "Effects of tunnelling current on mm-wave IMPATT devices," International Journal of Electronics. In press.

[25] A. Acharyya, M. Mukherjee, and J. P. Banerjee, "Influence of tunnel current on DC and dynamic properties of silicon based terahertz IMPATT source," Terahertz Science and Technology, vol. 4, no. 1, pp. 26-41, 2011.

[26] A. Acharyya, M. Mukherjee, and J. P. Banerjee, "Studies on the millimeter-wave performance of MITATTs from avalanche transit time phase delay," in Proceedings of the IEEE Applied Electromagnetics Conference, pp. 1-4, Kolkata, India, December 2011.

[27] S. R. Pattanaik, J. K. Mishra, and G. N. Dash, "A new mm-wave $\mathrm{GaAs} \sim \mathrm{Ga}_{0.52} \mathrm{In}_{0.48}$ P Heterojunction IMPATT diode," IETE Journal of Research, vol. 57, no. 4, pp. 351-356, 2011.

[28] A. Acharyya and J. P. Banerjee, "Prospects of IMPATT devices based on wide bandgap semiconductors as potential terahertz sources," Applied Nanoscience, 2012.

[29] A. Acharyya and J. P. Banerjee, "Potentiality of IMPATT devices as terahertz source: an avalanche response time based approach to determine the upper cut-off frequency limits," IETE Journal of Research, vol. 59, no. 2, pp. 1-10, 2013.

[30] A. Acharyya, S. Banerjee, and J. P. Banerjee, "Optical control of millimeter-wave lateral double-drift region silicon IMPATT device," Radioengineering, vol. 21, no. 4, pp. 1208-1217, 2012.

[31] A. Acharyya and J. P. Banerjee, "Analysis of photo-irradiated double-drift region silicon impact avalanche transit time devices in the millimeter-wave and terahertz regime," Terahertz Science and Technology, vol. 5, no. 2, pp. 97-113, 2012.

[32] G. N. Dash, J. K. Mishra, and A. K. Panda, "Noise in mixed tunneling avalanche transit time (MITATT) diodes," Solid-State Electronics, vol. 39, no. 10, pp. 1473-1479, 1996.

[33] A. Acharyya, M. Mukherjee, and J. P. Banerjee, "Noise in millimeter-wave mixed tunneling avalanche transit time diodes," Archives of Applied Science Research, vol. 3, no. 1, pp. 250-266, 2011.

[34] A. Acharyya, M. Mukherjee, and J. P. Banerjee, "Noise performance of millimeter-wave silicon based mixed tunneling avalanche transit time (MITATT) diode," International Journal of Electrical and Electronics Engineering, vol. 4, no. 8, pp. 577584, 2010.

[35] W. N. Grant, "Electron and hole ionization rates in epitaxial Silicon," Solid-State Electronics, vol. 16, no. 10, pp. 1189-1203, 1973.

[36] C. Canali, G. Ottaviani, and A. Alberigi Quaranta, "Drift velocity of electrons and holes and associated anisotropic effects in silicon," Journal of Physics and Chemistry of Solids, vol. 32, no. 8, pp. 1707-1720, 1971.
[37] J. Lee, A. L. G. Aitken, S. H. Lee, and P. K. Bhattacharya, "Responsivity and Impact ionisation coefficients of $\mathrm{Si}_{1-x} \mathrm{Ge}_{x}$ photodiodes," IEEE Electron Devices, vol. 43, no. 6, pp. 977-981, 1996.

[38] K. Yeom, J. M. Hincley, and J. Singh, "Calculation of electron and hole impact ionisation coefficients in SiGe alloys," Journal of Applied Physics, vol. 80, no. 12, pp. 6773-6782, 1996.

[39] M. Ershov and V. Ryzhii, "High field electron transport in SiGe alloy," Japanese Journal of Applied Physics, vol. 33, no. 3, pp. 1365-1371, 1994.

[40] T. Yamada and D. K. Ferry, "Montecarlo simulation of hole transport in strained $\mathrm{Si}_{1-x} \mathrm{Ge}_{x}$," Solid-State Electronics, vol. 38, no. 4, pp. 881-890, 1995.

[41] D. L. Scharfetter and H. K. Gummel, "Large-signal analysis of a silicon read diode oscillator," IEEE Transactions on Electron Devices, vol. 6, no. 1, pp. 64-77, 1969.

[42] J. F. Luy, A. Casel, W. Behr, and E. Kasper, "A 90-GHz doubledrift IMPATT diode made with Si MBE," IEEE Transactions on Electron Devices, vol. 34, no. 5, pp. 1084-1089, 1987.

[43] C. Dalle, P. A. Rolland, and G. Lieti, "Flat doping profile double-drift silicon IMPATT for reliable CW high-power highefficiency generation in the $94-\mathrm{GHz}$ window," IEEE Transactions on Electron Devices, vol. 37, no. 1, pp. 227-236, 1990.

[44] J. F. Luy, H. Jorke, H. Kibbel, A. Casel, and E. Kasper, "Si/SiGe heterostructure mitatt diode," Electronics Letters, vol. 24, no. 22, pp. 1386-1387, 1988. 

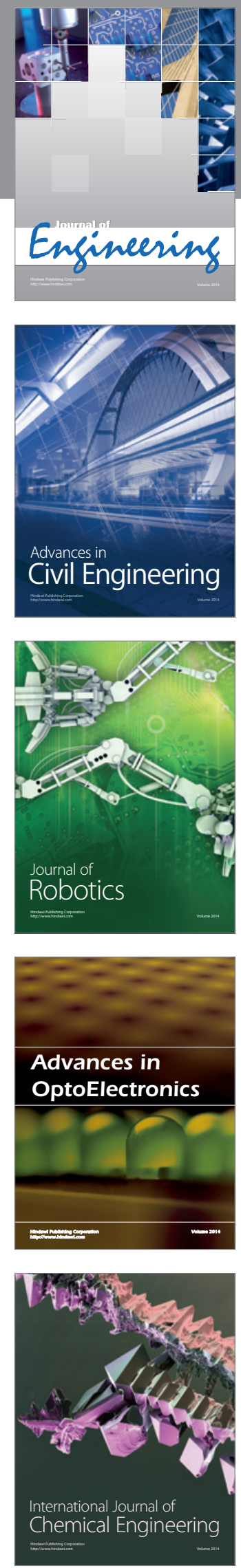

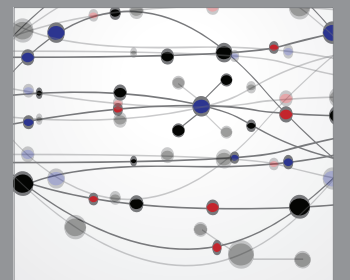

The Scientific World Journal
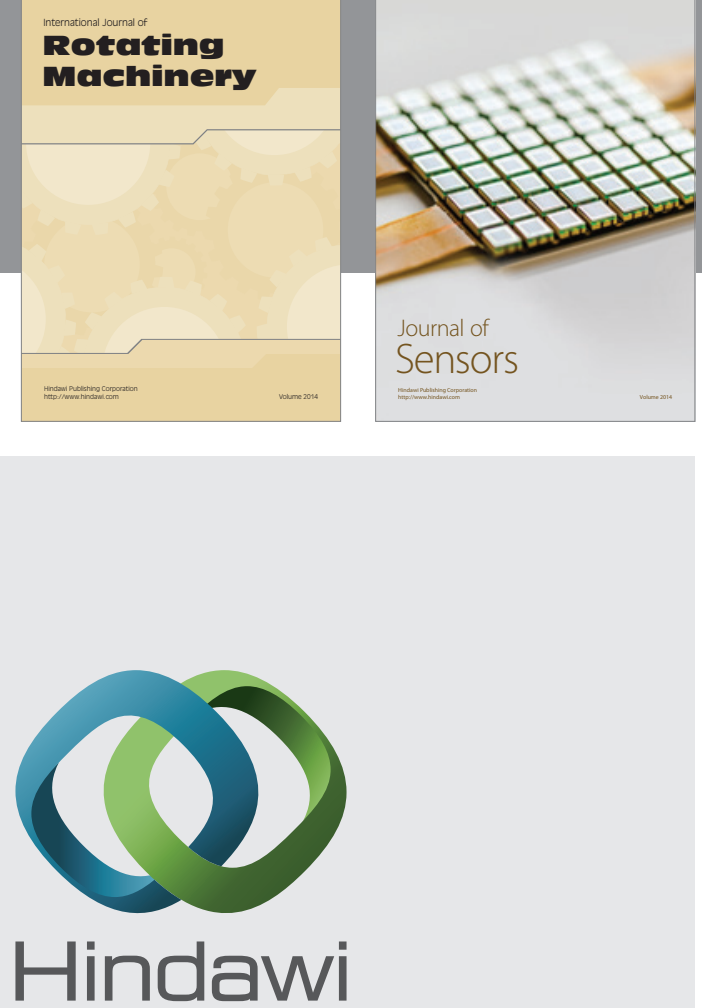

Submit your manuscripts at http://www.hindawi.com
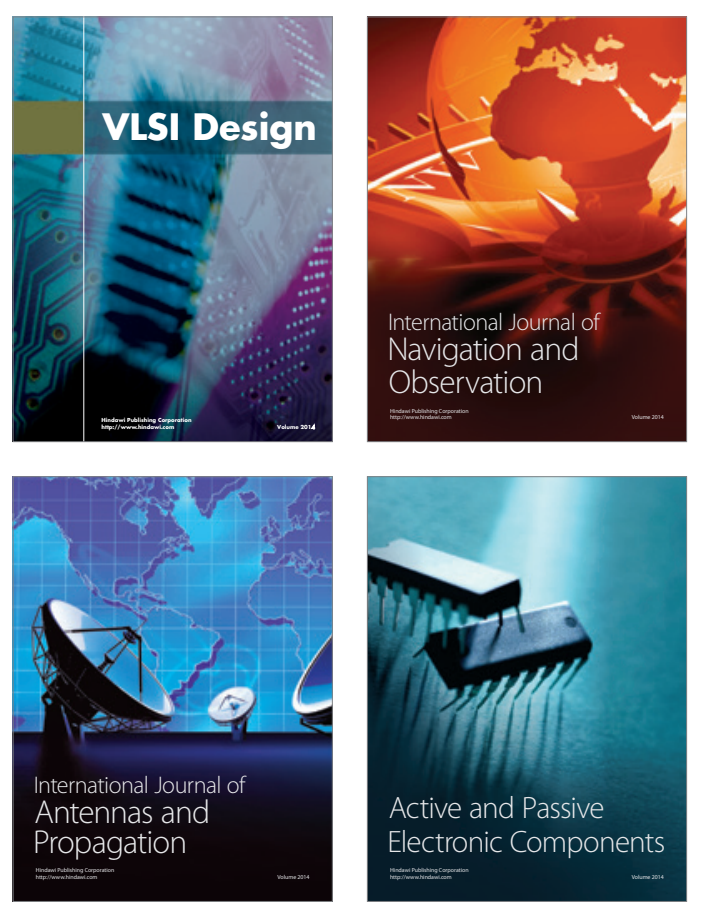
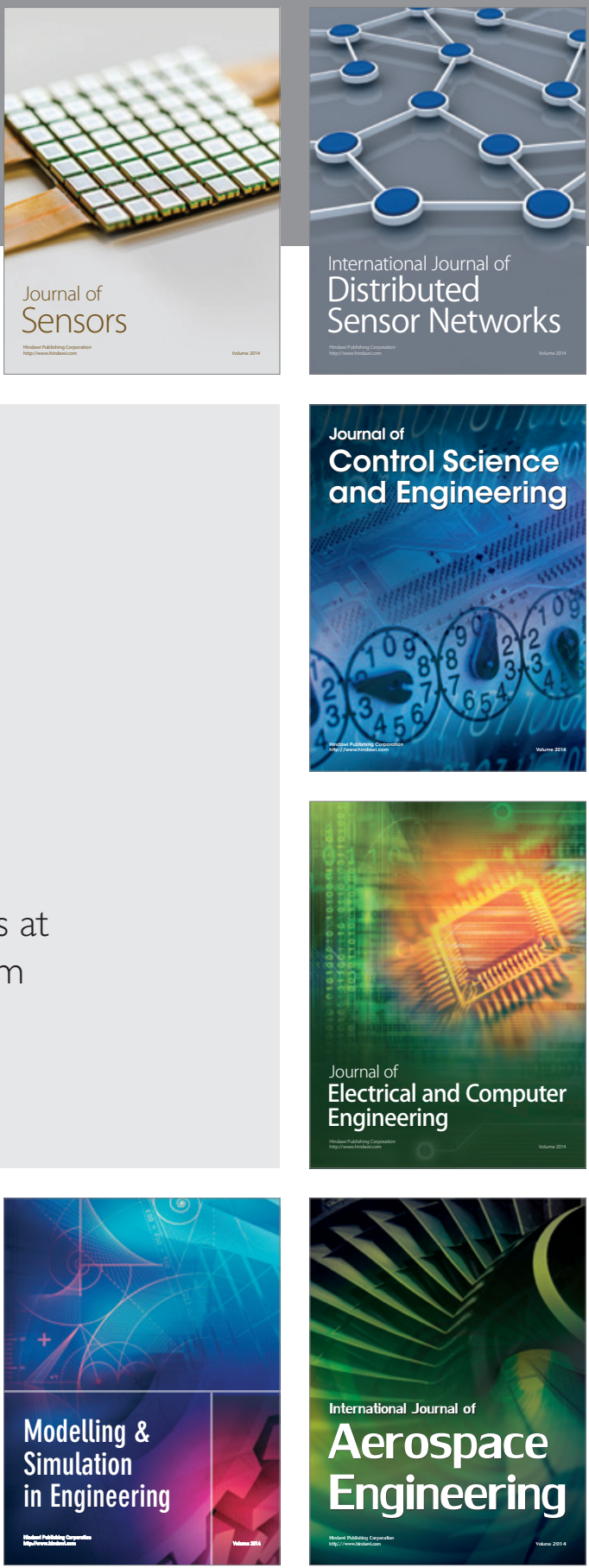

Journal of

Control Science

and Engineering
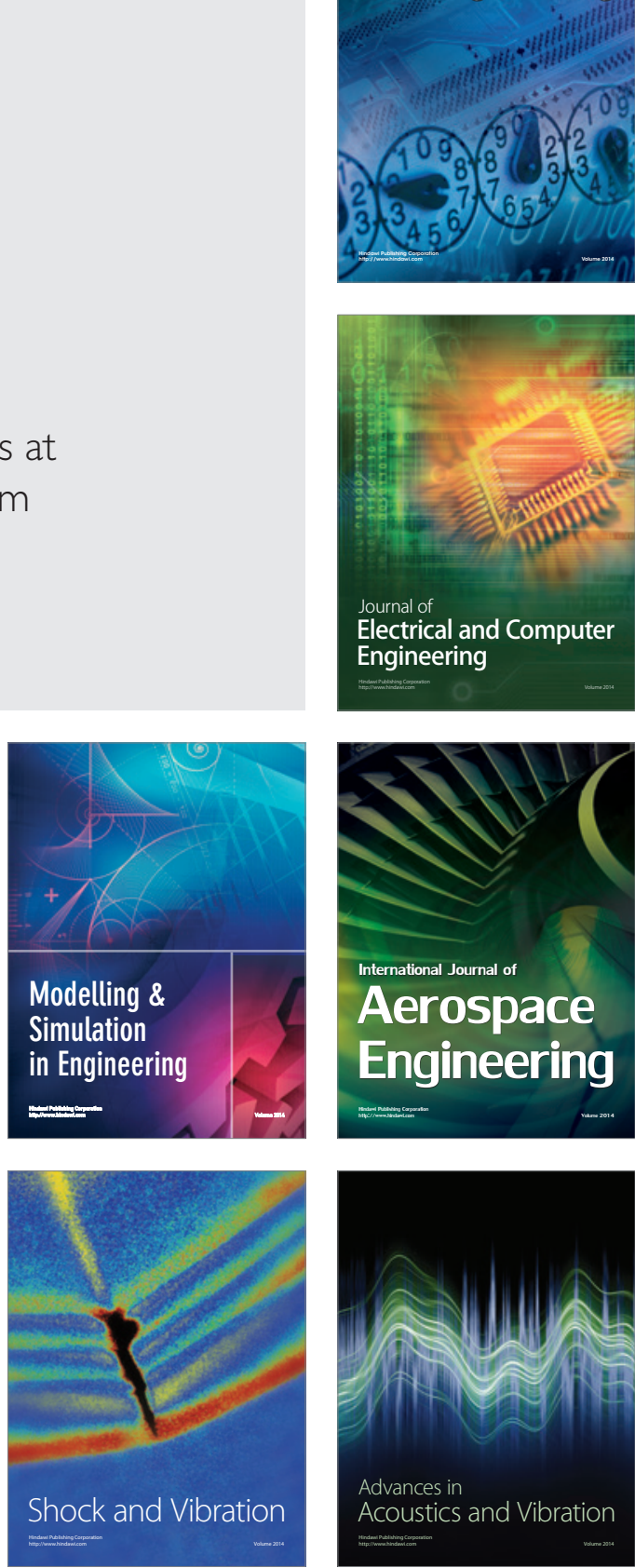